\title{
Evaluation of non-HIV-related, drug-sensitive cluster outbreaks of tuberculosis with PCR-based DNA fingerprinting
}

\author{
JM FITZGERALD MB FRCPC ${ }^{*}$, WA BLACK MB FRCPC ${ }^{\dagger}$, D KUNIMOTO MD FRCPC ${ }^{\ddagger}$ \\ ${ }^{*}$ Respiratory Division, Department of Medicine, University of British Columbia, Vancouver and \\ ${ }^{*}$ Provincial TB Laboratory, BC Centre for Disease Control, Ministry of Health, Vancouver, \\ British Columbia; and ${ }^{\ddagger}$ Department of Medical Microbiology and Infectious Disease, \\ University of Alberta, Edmonton, Alberta
}

JM FitzGerald, WA BLACK, D Kunimoto. Evaluation of non-HIV-related, drug-sensitive cluster outbreaks of tuberculosis with PCR-based DNA fingerprinting. Can Respir J 1996;3(5):317-321.

OBJECTIVES: To characterize two cluster outbreaks of tuberculosis by DNA fingerprinting and to evaluate the possibility of their association with human immunodeficiency virus (HIV) infection and multiple drug-resistant Mycobacterium tuberculosis.

SETTING: Two clusters of tuberculosis cases in adjoining aboriginal Canadian reserves and a control population.

METHODS: All cases of tuberculosis diagnosed in the two communities and a number of control isolates were fingerprinted using a novel simplified DNA-based technique. Demographic data, purified protein derivative (PPD) skin test response to 5TU PPD, type of disease and HIV serology were also evaluated. Positive cultures were assessed for susceptibility to antituberculous drugs.

RESULTS: Two distinct clusters with five cases in one community and 21 cases in the second were identified. Isolates from both communities differed in their DNA pattern but were identical within communities. Thirteen cases had bacteriologically proven disease and grew susceptible organisms. Serological analysis for HIV infection was carried out in 15 of 18 adults, and all were negative.

CONCLUSIONS: The study shows the potential for the rapid transmission of tuberculosis infection in HIVnegative subjects with susceptible organisms. It further highlights the usefulness of DNA fingerprinting for molecular epidemiology in evaluating particular outbreaks.

Key Words: Cluster outbreaks, PCR-based fingerprinting, Tuberculosis

Évaluation de flambées de cas isolés de tuberculose non liée au VIH et sensible à la médication antituberculeuse, par empreinte génétique de l'ADN basée sur la technique de la PCR

OBJECTIFS : Caractériser deux flambées de cas isolés de tubervoir page suivante 
culose par empreinte génétique de l'ADN et évaluer l'éventualité de leur association à une infection par le virus de l'immunodéficience humaine (VIH) et à Mycobacterium tuberculosis multirésistant aux médicaments.

CONTEXTE : Deux grappes de cas de tuberculose dans des réserves adjacentes d'aborigènes canadiens et une population témoin. MÉTHODES : Tous les cas de tuberculose diagnostiqués dans les deux communautés et un nombre d'isolats témoins ont été évalués par empreinte génétique reposant sur une nouvelle technique simplifiée d'identification de l'ADN. Les données démographiques, la réaction au test cutané à la tuberculine à 5 U.T. de PPD, le type de maladie et une sérologie pour le VIH ont aussi été évalués. Les cultures positives ont été examinées relativement à leur susceptibilité aux agents antituberculeux.
RÉSULTATS : Deux grappes distinctes de 5 cas dans une communauté et de 21 cas dans la seconde ont été identifiées. Les isolats provenant des deux communautés différaient dans la structure de leur $\mathrm{ADN}$ mais étaient identiques à l'intérieur de chacune des communautés. Une tuberculose active a été démontrée à la culture dans 13 cas chez lesquels les organismes se sont révélés sensibles aux antituberculeux. Une analyse sérologique visant à dépister une infection par le VIH a été pratiquée chez 15 adultes sur 18. Tous les sujets testés étaient séronégatifs.

CONCLUSIONS : L'étude démontre qu'une transmission rapide de l'infection tuberculeuse avec des organismes sensibles, chez des sujets séronégatifs pour le VIH est possible. En outre, elle démontre également l'utilité de l'empreinte génétique de l'ADN en épidémiologie moléculaire pour évaluer les flambées particulières.
$\mathrm{T}$ here is concern regarding an increased prevalence of tuberculosis (TB) in both developed and developing countries (1). Much of this increase is thought to be associated with human immunodeficiency virus (HIV) infection (2). In the United States multidrug-resistant TB (MDRTB) has particularly been a problem (3). Recent reports of studies using DNA-based technology have shown rapid transmission of infection and development of MDRTB in the presence of HIV infection (4). In addition, population-based molecular epidemiology studies have shown greater transmission of disease than previously thought $(5,6)$.

Among aboriginal Canadians there is a high prevalence of TB - approximately 10 times the rate among the general population $(90 / 100,000$ versus nine/100,000 population, respectively) (7). So far MDRTB and HIV infection have not been major problems in this group (8), although recent trends indicate that this may be changing (9). We recently investigated a number of cluster outbreaks of TB in this population group (10); two were geographically close, occurring approximately $5 \mathrm{~km}$ apart.

We were interested in establishing the prevalence of HIV infection in both clusters, the drug susceptibility patterns, and finally whether there was any link between the two outbreaks by using a novel DNA-based technique, which has been recently described (11).

\section{PATIENTS AND METHODS}

All cases of TB diagnosed in both communities between January and December 1992 were identified. Demographic data, risk factors for TB, response to purified protein derivative of tuberculin (5TU PPD), chest x-ray findings, HIV serology, bacteriological results and drug susceptibility patterns were collected. Sputum and pleural fluid were cultured using the Bactec technique. Specimens that were positive on culture for Mycobacterium tuberculosis were processed for strain identification.

A newly described method using a ligation-mediated polymerase chain reaction (PCR) procedure was used to amplify the flanking sequences on both sides of the insertion sequence 6110 from restriction-digested chromosomal DNA. This method has recently been described in detail (11). Briefly, this process involves inactivating the mycobacteria with phenol and breaking open the mycobacteria by vortexing in the presence of glass beads. The debris are then pelleted and the DNA supernatant is purified by adherence to glass powder. After restriction enzyme digestion a linker is ligated to the cut ends. Primers homologous to the insertion sequence 986 and the linker are then used in PCR and the products run on an agarose gel. The results are characteristic patterns of multiple bands of different lengths depending on the distance from the insertion sequences to the external restriction sites.

\section{RESULTS}

Two distinct clusters with five cases in one community and 21 cases in the second were identified. Isolates from both communities differed in their DNA pattern but were identical within communities. Thirteen cases had bacteriologically proven disease and grew fully sensitive organisms. Serological analysis for HIV infection was carried out for 15 of 18 adults; all were negative. All subjects were interviewed by one investigator, and the contact evaluation records for each outbreak were reviewed in the British Columbia Centre for Disease Control, Tuberculosis Division.

Cluster A: Both index and source case in cluster A was a 22-year-old male. Details of other cases diagnosed within the community are given in Table 1 . He presented with a selfreported cough of six weeks' duration in May 1992, but a history of coughing for at least six months was subsequently obtained from family members. He denied a history of intravenous drug use. In this community there were 21 cases (12 male). All but four had symptoms; 13 had documented PPD conversion, having been negative on PPD skin testing at initial screening in the community or having previously been known to be negative from prior tuberculin records. Followup PPD skin tests were carried out when subjects presented with symptoms or where follow-up PPD skin testing at least three months after the initial screening was carried out. Recently documented PPD conversion indicated recent infection. Seven others had a positive PPD to $5 \mathrm{TU}$ at presentation. HIV serology was completed in 12 of 15 adults and was negative in all. Disease was confirmed by mycobacteriology in 10 cases and all had drug-susceptible organisms.

Cluster B: The index case in cluster B was an infant aged 20 
TABLE 1

Characteristics of individuals in cluster $A$ who were in contact with the index case (number 1)

\begin{tabular}{|c|c|c|c|c|c|c|c|}
\hline $\mathbf{n}$ & $\operatorname{Sex}(M / F)$ & Age (years) & Symptoms & PPD* & CXR & HIV & Bacteriology \\
\hline 1 (index) & $M$ & 22 & 6 weeks & $17 \mathrm{~mm}$ & Pulmonary & & - \\
\hline 2 & $\mathrm{~F}$ & 13 & 4 months & $0-6 \mathrm{~mm}$ & Primary & ND & None \\
\hline 3 & M & 26 & 6 months & $0-22 \mathrm{~mm}$ & Pulmonary & & - \\
\hline 4 & $\mathrm{~F}$ & 14 months & None & $0-20 \mathrm{~mm}$ & Primary & ND & None \\
\hline 5 & $\mathrm{~F}$ & 6 & 2 months & $15 \mathrm{~mm}$ & Primary/Pleural & ND & None \\
\hline 6 & M & 21 & Yes & $14 \mathrm{~mm}$ & Pulmonary & & - \\
\hline 7 & M & 21 & 2 weeks & $20 \mathrm{~mm}$ & Pulmonary & - & - \\
\hline 8 & $\mathrm{~F}$ & 19 & 1 week & $0-20 \mathrm{~mm}$ & Pleural & & - \\
\hline 9 & M & 22 & 2 weeks & $0-18 \mathrm{~mm}$ & Pleural & & - \\
\hline 10 & $\mathrm{~F}$ & 4 & None & $0-10 \mathrm{~mm}$ & Primary & ND & None \\
\hline 11 & M & 23 & 3 months & ND & Primary/Pulmonary & & - \\
\hline 12 & M & 35 & 3 weeks & $0-28 \mathrm{~mm}$ & Pulmonary & - & - \\
\hline 13 & $M$ & 27 & 6 weeks & $27 \mathrm{~mm}$ & Pulmonary & & - \\
\hline 14 & $\mathrm{~F}$ & 19 & 6 weeks & $0-22 \mathrm{~mm}$ & Pulmonary/Pleural & & - \\
\hline 15 & M & 5 & 2 weeks & 0-19 mm & Primary & ND & - \\
\hline 16 & $\mathrm{~F}$ & 22 & 4 weeks & $0-28 \mathrm{~mm}$ & Primary/Pleural & & - \\
\hline 17 & M & 3 & None & $20 \mathrm{~mm}$ & Primary & ND & None \\
\hline 18 & $\mathrm{~F}$ & 23 & 1 month & $0-20 \mathrm{~mm}$ & Pleural/Primary & & - \\
\hline 19 & $\mathrm{~F}$ & 17 & 1 week & $0-23 \mathrm{~mm}$ & Pleural/Primary & ND & - \\
\hline 20 & M & 19 & None & $0-13 \mathrm{~mm}$ & Primary & ND & - \\
\hline 21 & M & 18 & 2 months & $16 \mathrm{~mm}$ & Pulmonary & ND & - \\
\hline
\end{tabular}

${ }^{*} T$ wo readings indicate purified protein derivative (PPD) conversion during the contact evaluation. CXR Chest $x$-ray; F Female; HIV Human immunodeficiency virus; M Male; ND Not done

TABLE 2

Characteristics of individuals in cluster $B$ who were in contact with the source case (number 1)

\begin{tabular}{|c|c|c|c|c|c|c|c|}
\hline $\mathbf{n}$ & $\operatorname{Sex}(M / F)$ & Age (years) & Symptoms & PPD* & CXR & HIV & Bacteriology \\
\hline 1 (source) & M & 45 & 18 months & $10 \mathrm{~mm}$ & Cavitary pulmonary disease & & - \\
\hline 2 & M & 20 & 4 weeks & $0-11 \mathrm{~mm}$ & Pleural effusion & - & - \\
\hline 3 & $\mathrm{~F}$ & 16 & None & $0-12 \mathrm{~mm}$ & Primary tuberculosis & ND & - \\
\hline 4 (index) & $\mathrm{F}$ & 20 months & 6 months & ND & Progressive primary & & ND \\
\hline 5 & $\mathrm{~F}$ & 16 & none & $17 \mathrm{~mm}$ & Progressive primary & & - \\
\hline
\end{tabular}

${ }^{*} T$ wo readings indicate purified protein derivative (PPD) conversion during the contact evaluation. CXR Chest $x$-ray; F Female; HIV Human immunodeficiency virus; M Male; ND Not done

months who presented with recurrent pneumonia. Characteristics of the other cases diagnosed in this community are shown in Table 2. Eventually the infant had gastric washings obtained for mycobacteriology and these grew M tuberculosis. Reverse contact tracing identified the father of the infant's babysitter as the source case. He had bilateral apical abnormalities noted 18 months previously but at that time he refused to attend for further evaluation. He had a history of intravenous drug use. Three further cases, all asymptomatic, were identified in contact tracing. Two had PPD conversions and one had a positive PPD at evaluation. Three subjects had susceptible, bacteriologically proven disease. The remaining subjects had primary disease. The three adults in this cluster were HIV-negative.

DNA fingerprinting: The isolates from both communities were found to differ, showing two unique patterns. Twelve control specimens, drawn at random from cases diagnosed throughout the same period and evaluated at the same time, were all different. The exceptions were isolates from two
HIV-negative brothers who had the same PCR pattern, which was different from those in the clusters. The control specimens were obtained to provide internal validity, further blinding the laboratory to the epidemiological data. Gel electrophoresis patterns produced by a sample of control and cluster case isolates from cluster A are shown in Figure 1.

\section{DISCUSSION}

TB is reemerging as a major health concern in both developed and developing countries (1). Traditionally it has been thought that the majority of newly diagnosed cases represented reactivation of previously acquired infection (12), although exogenous reinfection with a new organism has been described using phage typing (13). New insight into the transmission of TB infection has been gained by evaluating clusters of HIV-associated cases in whom infection with a resistant organism has been acquired while on therapy for drug-susceptible disease (4). 


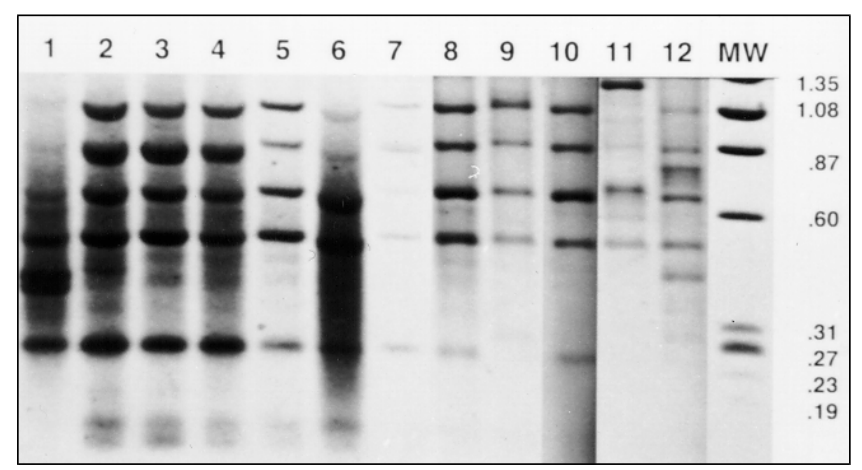

Figure 1) Mycobacterial DNA patterns after ligase-mediated polymerase chain reaction. Lane 1 is an unrelated control, lanes 2 to 12 are from patients identified as epidemiologically related to cluster 1 and lane 13 is a molecular weight (MW) marker. Lanes 2 to 10 have identical patterns

In addition, population-based studies using restriction fragment length polymorphism as a fingerprinting technique have indicated that between $30 \%$ and $40 \%$ (6) of all newly diagnosed cases of disease are related. This indicates that, contrary to the traditional belief that approximately $10 \%$ of new cases are due to recent acquisition of infection and progression to disease, much more infection transmission and progression to disease occurs than heretofore thought.

We report two separate clusters of TB cases with a total of 27 cases of active TB. Earlier non-HIV-related studies have tended to concentrate on methodological issues (14-16) and distinguishing among strains, but they have lacked a large number of similar isolates and provided no epidemiological information.

The speed at which infection occurred and cases of active TB disease developed can be inferred from the chronological presentation of the active cases, especially in cluster A, following the diagnosis. Our data highlight the rapidity with which infection can be transmitted and disease develop even in non-HIV-infected subjects. This rapidity is further supported by the high proportion of subjects who had a conversion of their Mantoux PPD skin test responses while being evaluated, indicating that infection had recently been acquired. The two distinct patterns in the clusters support two different sources for the two outbreaks.

Paradoxically the source case in cluster A reported the shorter history of symptoms but generated the larger number of cases. Although the frequent communal events on a North American Indian reserve and the generally poor standard of housing may have facilitated the rapid transmission of infection, the total number of cases identified is significant. It highlights the importance of early diagnosis of TB and prompt initiation of therapy (17). Because of the potential for transmission of infection within the community, it is possible that the homogeneity of isolates evaluated from this cluster outbreak could be due to a tendency of isolates on aboriginal reserves to be similar. This hypothesis is disproved by the heterogeneity of isolates from a number of Northern Alberta communities (unpublished data).

A corollary of these data is that in cluster situations, as de- scribed, the risk of progression from infection to disease in certain epidemiological situations is that much greater and reinforces the need to consider prompt chemoprophylaxis (18). It highlights the importance of promptly evaluating contacts of all active cases of TB and promptly initiating chemoprophylaxis. For one patient in cluster A there was a twomonth delay between having a normal chest $\mathrm{x}$-ray and PPD conversion, and being offered chemoprophylaxis and initiating it. A short time after chemoprophylaxis was started the subject presented with a pleural effusion. The physician who assessed her did not consider TB as a possibility and continued the patient on isoniazid while the presumptive diagnosis of a parapneumonic effusion was being evaluated. Six weeks later the patient presented with a TB empyema which grew a fully sensitive organism. After decortication and a full course of anti-TB therapy there was complete resolution of the abnormalities.

The clustering of cases among aboriginal patients is likely multifactorial and, although our data do not address the issue of housing, it is likely that better housing and community education regarding TB would facilitate a reduction in the overall rates in these communities.

Although much of our attention has focused on HIV-related TB, this report highlights the rapid progression to disease that can occur in the absence of HIV infection and with fully susceptible organisms. The availability of DNA fingerprinting of responsible organisms provides a useful epidemiological tool for evaluating such outbreaks and casts new light upon the pathogenesis of TB.

\section{REFERENCES}

1. Kochi A. The global tuberculosis situation and the new control strategy of the World Health Organization. Tubercle 1991;72:1-6.

2. FitzGerald J, Grzybowski S, Allen EA. The impact of human immunodeficiency virus infection on tuberculosis and its control. Chest 1991;100:191-200.

3. Daley CL, Small PM, Schecter GF, et al. An outbreak of tuberculosis with accelerated progression among persons infected with the human immunodeficiency virus. An analysis using restriction fragment length polymorphism. N Engl J Med 1992;326:231-5.

4. Small P, Shafer RW, Hopewell PC, et al. Exogenous reinfection with multidrug resistant Mycobacterium tuberculosis in patients with advanced HIV infection. N Engl J Med 1993;328:1137-44.

5. Genewein A, Telenti A, Bernasconi C, et al. Molecular approach to identifying route of transmission of tuberculosis in the community. Lancet 1993;342:841-4.

6. Small PM, Hopewell PC, Singh SP, et al. The epidemiology of tuberculosis in San Francisco. A population based study using conventional and molecular methods. N Engl J Med 1994;330:1703-9.

7. FitzGerald JM, Dy Buncio A, Branckner A. Recent trends in TB in Canada: the potential impact of HIV infection. Am Rev Respir Dis 1993;147(Suppl):A118. (Abst)

8. Korzeniewska-Kosela M, FitzGerald JM, Vedal S, et al. Spectrum of tuberculosis in patients with HIV infection in British Columbia: A report of forty cases. Can Med Assoc J 1992;146:1927-34.

9. Blenkush M, Korzeniewska-Kosela M, Elwood RK, Black W, FitzGerald JM. HIV related tuberculosis in British Columbia: indications of a rise and change in risk groups. Am J Respir Crit Care Med 1995;151:A510. (Abst)

10. FitzGerald JM. A preliminary report of three cluster outbreaks of tuberculosis in British Columbia. Can Commun Dis Rep 1994;20-1:1-3.

11. Palittapongarnpim P, Chomyc S, Fanning A, Kunirnoto D. DNA fingerprinting of Mycobacterium tuberculosis isolates by 
ligation-mediated polymerase chain reaction. Nucleic Acids Res 1993;21:761-2.

12. Nardell EA. Pathogenesis of tuberculosis. In: Reichman LB, Hershfield ES, eds. Tuberculosis: A Comprehensive International Approach. New York: Marcel Dekker Inc, 1993:103-22.

13. Nardell E, McInnis B, Weidhaas S. Exogenous re-infection with tuberculosis in a shelter for the homeless. N Engl J Med 1986;315:1570-5

14. Zhang Y, Mazurek GH, Cave DM, et al. DNA polymorphisms in strains of Mycobacterium tuberculosis analysed by pulsed-field gel electrophoresis: a tool for epidemiology. J Clin Microbiol 1992;30:1551-6.

15. Hermans PW, Van Soolingen D, Dale JW, et al. Insertion element
IS986 from Mycobacterium tuberculosis: a useful tool for diagnosis and epidemiology of tuberculosis. J Clin Microbiol 1990;28:2051-8.

16. Van Soolingen D, Hermans PW, De Haas PE, Soll DR, Van Embden JD. Occurrence and stability of insertion sequences in Mycobacterium tuberculosis complex strains: evaluation of an insertion

sequence-dependent and polymorphism as a tool in the epidemiology of tuberculosis. J Clin Microbiol 1991;29:2578-86.

17. FitzGerald JM, Allen EA, Fanning A, et al. Essentials of tuberculosis control for the practising physician. Can Med Assoc J 1994;150:1561-71.

18. FitzGerald JM, Gafni A. A cost effectiveness analysis of the routine use of isoniazid prophylaxis in patients with a positive Mantoux skin test. Am Rev Respir Dis 1990;142:848-53. 


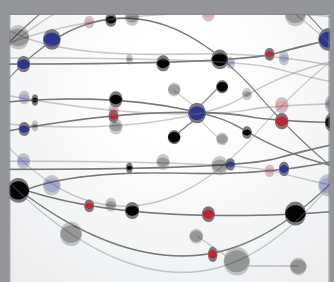

The Scientific World Journal
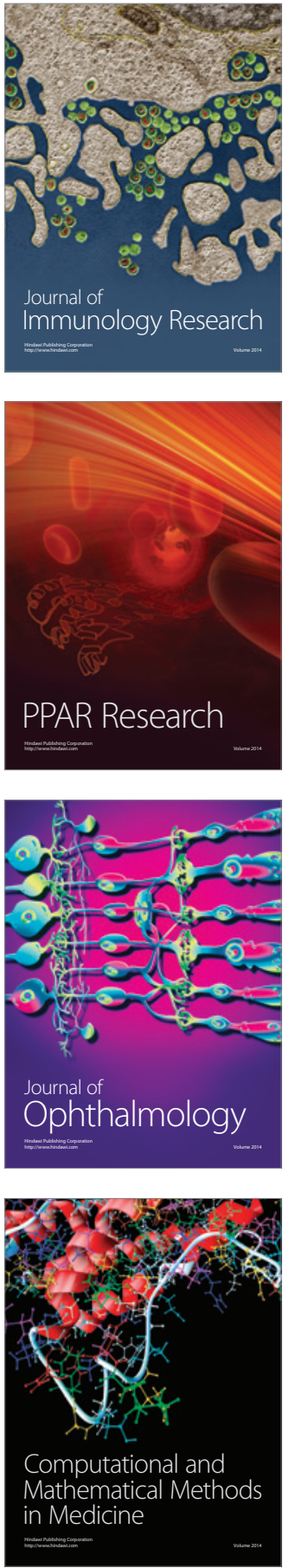

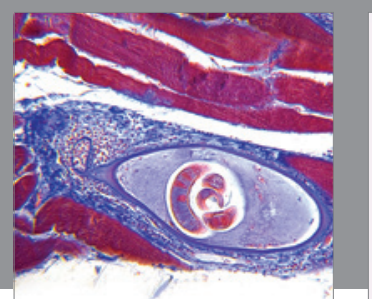

Gastroenterology Research and Practice

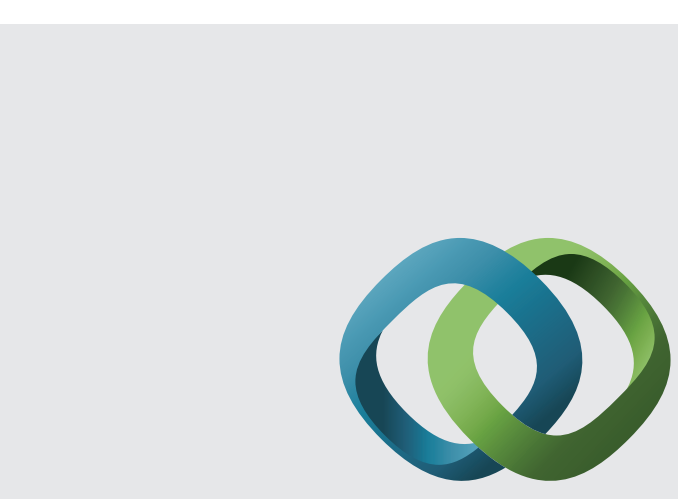

\section{Hindawi}

Submit your manuscripts at

http://www.hindawi.com
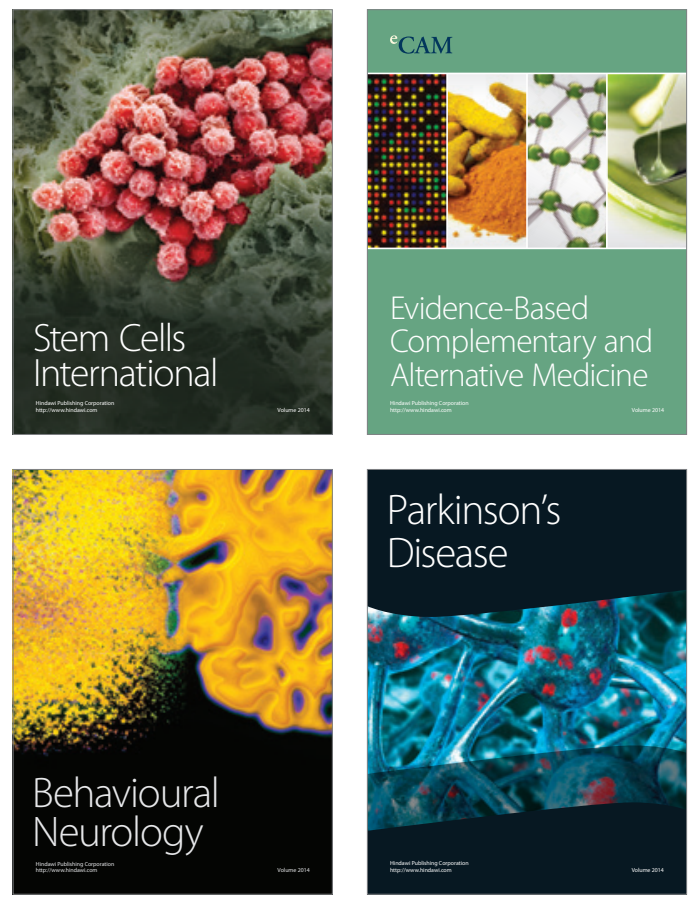
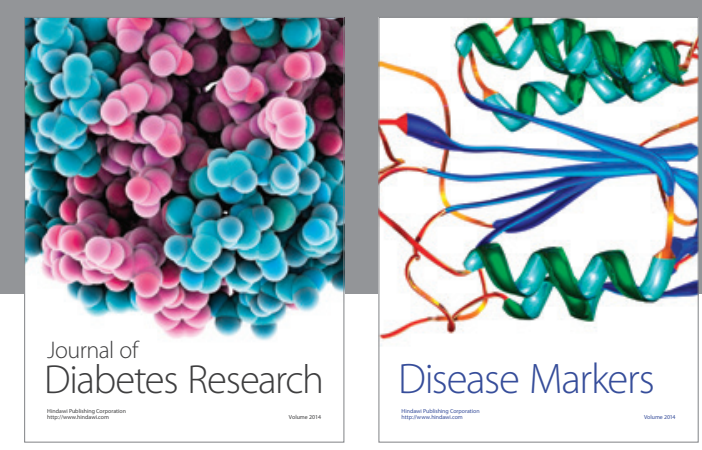

Disease Markers
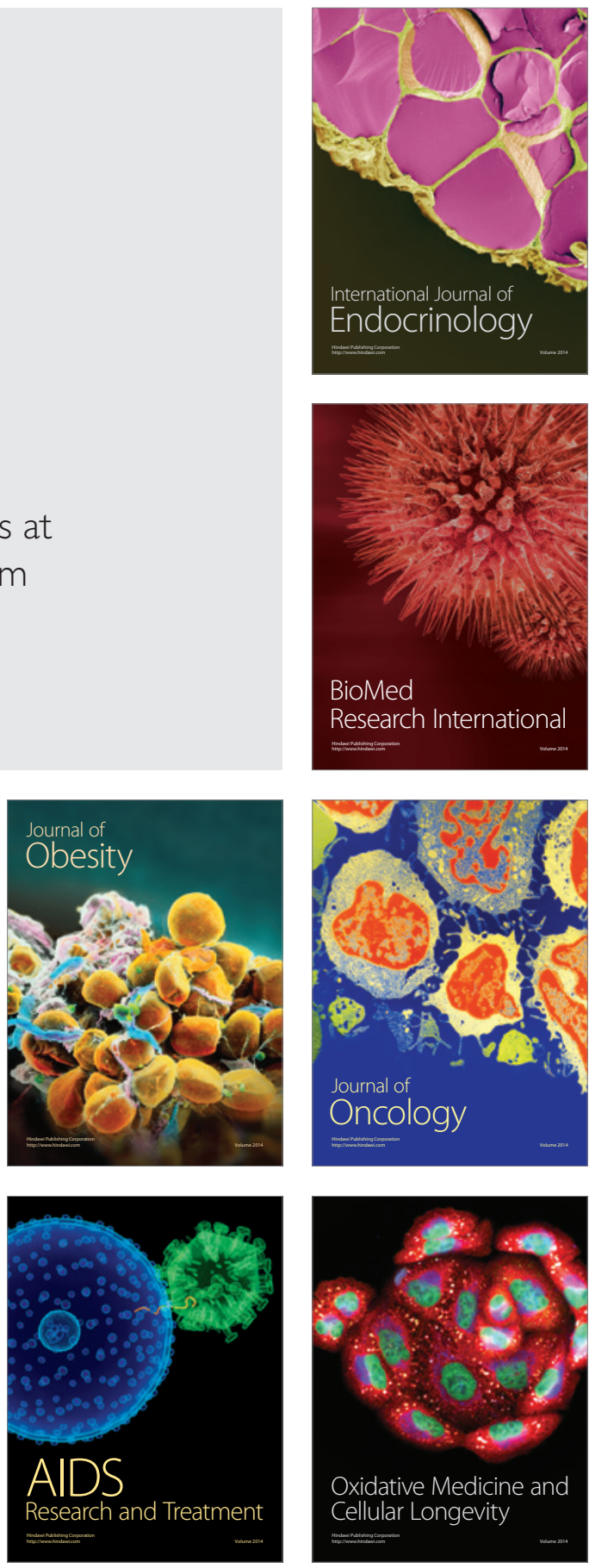